\title{
Application of Normalized Difference Vegetation Index (NDVI) for the Detection of Extreme Precipitation Change
}

\author{
Fengsong Pei * (D), Yi Zhou (D) and Yan Xia \\ School of Geography, Geomatics and Planning, Jiangsu Normal University, Xuzhou 221116, China; \\ yzhou@jsnu.edu.cn (Y.Z.); xiayan@jsnu.edu.cn (Y.X.) \\ * Correspondence: peifs@jsnu.edu.cn
}

check for

updates

Citation: Pei, F.; Zhou, Y.; Xia, Y. Application of Normalized Difference Vegetation Index (NDVI) for the Detection of Extreme Precipitation Change. Forests 2021, 12, 594 . https://doi.org/10.3390/f12050594

Received: 28 March 2021

Accepted: 6 May 2021

Published: 9 May 2021

Publisher's Note: MDPI stays neutral with regard to jurisdictional claims in published maps and institutional affiliations.

Copyright: (c) 2021 by the authors. Licensee MDPI, Basel, Switzerland. This article is an open access article distributed under the terms and conditions of the Creative Commons Attribution (CC BY) license (https:/ / creativecommons.org/licenses/by/ $4.0 /)$.

\begin{abstract}
Remote sensing has frequently been employed to monitor extreme climatic events, especially droughts, by identifying the anomalies of vegetation activity from the regional to global scale. However, limited research has addressed the performance of remote sensing on detecting extreme precipitation events. By using the Middle and Lower Reaches of the Yangtze River (MLR-YR) in China as an example, this paper examines the application of the satellite-derived normalized difference vegetation index (NDVI) for detecting the change of extreme precipitation events from 1982 to 2012. The performances of three NDVI-based indices, including minimum, mean, and maximum NDVIs, were examined to capture the sensibility of vegetation activity to changes in extreme precipitation events. The results show not only common enhanced trends, but also obvious spatial discrepancies between the intensity and frequency of extreme precipitation events in the MLR-YR. As to its application on terrestrial vegetation, changes in extreme precipitation intensity coincided with that of the vegetation activity, which was represented as the maximum and the minimum NDVIs, especially the maximum NDVI. In addition, similar patterns were found between the standard deviation of the maximum NDVI and the trend of extreme precipitation intensity. Furthermore, the correlation coefficients were relatively greater between the maximum NDVI and extreme precipitation intensity than that of the minimum NDVI. Our results support the hypothesis that maximum NDVI is more suited to capture the response of vegetation activity to extreme precipitation events in the MLR-YR region, in comparison to the other two NDVI indices.
\end{abstract}

Keywords: extreme precipitation events; vegetation activity; normalized difference vegetation index; performance assessment; the middle and lower reaches of the Yangtze River

\section{Introduction}

According to the Special Report in the Sixth Assessment Report of the Intergovernmental Panel on Climate Change (IPCC), mean land surface air temperature has increased by $1.53{ }^{\circ} \mathrm{C}\left(1.38\right.$ to $\left.1.68{ }^{\circ} \mathrm{C}\right)$ from $1850-1900$ to $2006-2015$, and this increase may even accelerate in the coming decades [1]. In such contexts, extreme climatic events were projected to be more frequent and intensive in future decades [2,3]. An extreme climatic event refers to the occurrence of a phenomenon when a meteorological variable is above (or below) a given threshold near the upper (or lower) ends of its observed values [4]. Extreme climatic events frequently lead to famine, human suffering, death, and cause large economic losses [5,6]. It is of great importance to monitor extreme climatic events in order to mitigate the threat it poses. In comparison to long-term climate change, extreme climatic events frequently have serious impacts on vegetation activity owing to the severity of the extremes [7-9]. On the contrary, vegetation activity was frequently employed as a proxy to reflect changes in climate extremes [10,11].

Remote sensing is frequently employed to monitor vegetation activity and its response to climate changes on the regional to global scale. For instances, Nagai et al. (2010) explored the use of daily normalized difference vegetation index (NDVI) to understand 
the vegetation phenology response to short-term meteorological conditions [12]. Despite this, the daily temporal scale limits the use of the method to a large extent. In addition, Kogan (1990) developed the vegetation condition index (VCI) to extract short-term weather components, especially droughts, by normalizing weekly NDVI to the difference of NDVI extremes [10]. Furthermore, Kogan (1995) and Unganai et al. (1998) proposed the VT index by combining the VCI and temperature condition index (TCI) to monitor droughts $[13,14]$. The VCI and VT have been widely employed in monitoring the vegetation conditions associated with drought stresses $[15,16]$. As a satellite-derived data, NDVI demonstrated its usefulness when tracking weather and climate changes in past studies [7,17].

As to its application on extreme precipitation changes, many studies explored the relationships between mean NDVI values and extreme precipitation events. For instances, Tan et al. (2015) analyzed the correlations between mean NDVI values and extreme precipitation indices during 1982-2006 in the Poyang Lake Basin, China [18]. Cui et al. (2019) investigated the relationships between four extreme precipitation indices and annual mean NDVI using Pearson's correlation coefficients [19]. Besides the mean NDVI, maximum and minimum NDVIs were found to be able to respond to extreme precipitation events as well. According to Kogan et al. (2003), maximum and minimum NDVIs can capture the upper (favorable weather) and the lower (unfavorable weather) limits of the ecosystem resource in response to extreme weather events [20]. Potter and Brooks (1998) analyzed the relationships between monthly NDVI extremes (maximum and minimum values) and extreme rainfall across the globe [21]. Chamaillé Jammes and Fritz (2009) analyzed the relationships between precipitation and NDVI in eastern and southern African savannas using maximum and minimum NDVIs as proxies [22]. In addition, Fernandez-Carrillo et al. (2019) analyzed the correlations between cumulative 16-day rainfall and several indicators such as the minimum and maximum NDVIs [23]. Past studies preliminarily analyzed the relationships between various NDVI-based indices and extreme precipitation events. However, limited attention was paid to clarify the performances of different NDVI indices (i.e., minimum, mean, and maximum NDVIs) on capturing extreme precipitation change.

Taking the middle and lower reaches of the Yangtze River (MLR-YR) as an example, this paper aims to determine the optimal indicator from minimum, mean, and maximum NDVIs to capture extreme precipitation changes from 1982 to 2012. The commonly used NDVI datasets were mostly derived from NOAA AVHRR, MODIS, SPOT VEGETATION sensors, and so on. The NDVI products from different instruments vary in spatial resolution, temporal coverage and spectral range. The GIMMS NDVI3g dataset spans the period July 1981 to December 2015. Assuming a Generalized Pareto distribution (GPD) of precipitation excesses, extreme precipitation events were identified and examined from both perspectives of the extreme precipitation frequency and the extreme precipitation intensity, respectively. By using the GIMMS NDVI3g dataset, the performance of the three NDVI indices on detecting extreme precipitation events was analyzed using geographic information system (GIS) and statistical analysis. The findings can contribute to a fast monitoring of extreme precipitation events using remotely sensed data. In addition, it can be helpful to understand terrestrial vegetation response to extreme climate events as well.

\section{Study Area and Data Processing}

\subsection{Study Area}

The MLR-YR is located between $102-122^{\circ} \mathrm{E}$ and $24-34^{\circ} \mathrm{N}$, covering a total area of $1,157,057 \mathrm{~km}^{2}$ (Figure 1). The average annual temperature is $14-18{ }^{\circ} \mathrm{C}$, and total precipitation ranges between $1000 \mathrm{~mm}_{\text {year }}{ }^{-1}$ and $1500 \mathrm{~mm}_{\text {year }}{ }^{-1}$ in this region. It is subjected to frequent flooding events, such as those that occurred in 1954, 1998, and 2010 [24,25]. The MLR-YR, which is located in subtropical monsoon climatic zone, is characterized by a concurrent occurrence of rainfall and heat energy in the same seasons. The ecosystems in this region encompass evergreen broadleaf forest, evergreen needleleaf forest, shrubs, grasslands, cultivated vegetation, and so on. 


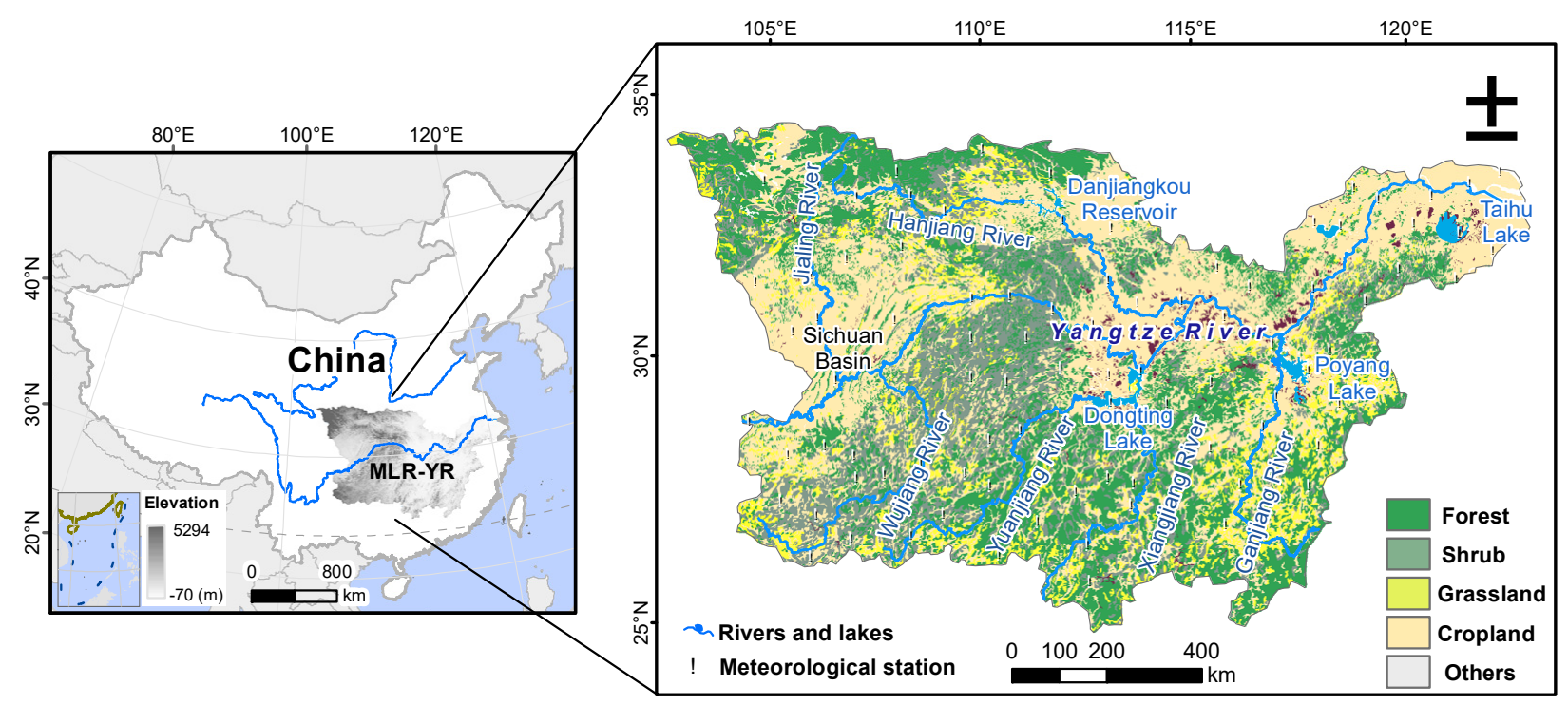

Figure 1. The location of the middle and lower reaches of the Yangtze River (MLR-YR).

\subsection{Data and Preprocessing}

The datasets in this study includes the meteorological dataset, NDVI data and land use/cover data in the MLR-YR. Concretely, the meteorological dataset, including daily precipitation and temperature data, was obtained from 1982 to 2012 from the China Meteorological Data Service Center (CMDC). To ensure data quality, the CMDC inspected the time consistency of the dataset and performed an extremum validation on it [26]. Furthermore, meteorological data with suspicious or missing records were excluded. On this basis, a total of 97 meteorological stations, which is nearly even-distributed in the study area, were selected to analyze changes in extreme precipitation events in this region (Figure 1).

As to the NDVI data, the third generation Advanced Very High Resolution Radiometer (AVHRR) NDVI dataset (i.e., NDVI3g), which was constructed by the Global Inventory Modelling and Mapping Studies (GIMMS) project, was obtained over the period 1982-2012 from the US National Aeronautics and Space Administration (NASA) Ames Ecological Forecasting Lab (https: / / ecocast.arc.nasa.gov/data/pub/gimms/, accessed on 8 December 2019). The dataset has a spatial resolution of $8 \mathrm{~km}$, and a temporal resolution of half a month. The AVHRR NDVI3g dataset was produced using maximum value compositing (MVC) to deal with deleterious effects of the first generation NDVI data (NDVIg), including calibration loss, orbital drift and volcanic eruptions $[27,28]$. To explicitly capture changes in vegetation activity, grid cells with annual mean NDVI less than 0.1 were masked out to exclude water, bare and sparsely vegetation. The NDVI in the growing season was then compiled using a time series of an NDVI dataset when the temperature is above $5^{\circ} \mathrm{C}$ [16].

In addition, land use/cover data in 2005, which covers the MLR-YR, were obtained at a spatial resolution of $500 \mathrm{~m}$ from the Moderate Resolution Imaging Spectroradiometer (MODIS) product (MCD12Q1). Concretely, the MCD12Q1 dataset in 2005 was downloaded from the NASA Land Processes Distributed Active Archive Center (LPDAAC), a part of NASA's Earth Observing System Data and Information System (https:/ / lpdaac.usgs.gov / products/mcd12q1v006/, accessed on 8 May 2020).

\section{Methods}

\subsection{The Peaks-Over-Threshold (POT) to Identify Extreme Precipitation Events}

Extreme Value Theory (EVT) was first developed by Fisher and Tippett (1928) to describe the characterization of extremes [29]. There are several ways to apply EVT to deal with climate extremes, including the Generalized Extreme Value (GEV) distribution and Peaks-Over-Threshold (POT) approach [30-33]. In the past decades, the POT approach was widely employed to detect extreme climatic events, including extreme temperature 
events, extreme precipitation events, and extreme wind velocity events [34-36]. In this paper, the POT approach was employed by prescribing the threshold of precipitation amount. The exceedances over the selected threshold were then analyzed to identify extreme precipitation events.

The selected threshold of daily precipitation amount determines not only the occurrence of a given extreme precipitation event, but also the sample size of the extreme precipitation events [37]. As pointed out by Pickands (1975), the exceedances over a threshold tend to converge to a generalized Pareto distribution, provided that the threshold value is high enough [38]. In past studies, different daily precipitation amounts were tested, and the 95th and 99th percentile of daily precipitation amount in rainy days was found to have a near-equidispersion dispersion coefficient in most stations in the MLR-YR [39]. Considering the three NDVI indices analysis in the growing season, extreme precipitation events at extreme wet days were analyzed [40]. Consequently, the 99th percentile of daily precipitation amount in rainy days was empirically employed as the threshold to identify extreme precipitation events in the MLR-YR from 1982 to 2012.

\subsection{The Frequency and the Intensity of Extreme Precipitation Events Using EPF and EPI as Proxies}

In this paper, changes in extreme precipitation events were analyzed in the MLR-YR from 1982 to 2012 from the perspectives of intensity and frequency, respectively. Many climate extreme indices were recommended by the Expert Team on Climate Change Detection and Indices (ETCCDI) to monitor the change in extreme precipitation events. The Rnnmm refers to the annual count of days when the daily precipitation amount exceeds a given threshold [41]. In this paper, extreme precipitation frequency was analyzed using the Rnnmm as a proxy. Assume that $P 1, P 2 \ldots P d$ are independent random observations of the daily precipitation amount. The extreme precipitation frequency $(E P F)$ in a given year was calculated as:

$$
E P F=\sum_{j=1}^{365} \tau_{y d}
$$

where $\tau_{y d}$ is a conditional function, which equals to one if daily precipitation $(P d)$ on the day $\mathrm{d}$ exceeds the prescribed threshold (i.e., the 99th percentile of daily precipitation amount). Otherwise, $\tau_{y d}$ becomes zero. On this basis, we use a Poisson regression model to detect the trend of extreme precipitation frequency in the MLR-YR during 1982-2012 [42-44]. Assuming that the amount of extreme precipitation events in a given year $\left(N_{y}\right.$, equals EPF in the year $y$ ) have a conditional Poisson distribution with the rate of occurrence, then:

$$
\mathrm{P}\left(\mathrm{N}_{y}=k \mid \lambda_{y}\right)=\frac{e^{-\lambda_{y}} \lambda_{y}^{k}}{k !}(k=0,1,2, \ldots)
$$

To quantify the temporal trend of extreme precipitation frequency, we fitted the $\lambda_{y}$ as a linear function of $y$ by using a logarithmic function (Equation (3)). It is expressed as:

$$
\lambda_{y}=\exp (a+b \cdot y)
$$

where both $a$ and $b$ are regression coefficients [43,44]. Furthermore, the simple index of extreme daily precipitation intensity was employed as a proxy of extreme precipitation intensity $(E P I)$ to characterize the severity of extreme precipitation events in the MLRYR [39]. Specifically, the EPI is calculated as:

$$
E P I_{t}=\frac{\sum_{d=1}^{365} P_{y d}}{N_{d}}, P_{y d}>u
$$

where $P_{y d}(\mathrm{~mm})$ represents daily precipitation amount in the year $y, N_{d}$ defines the number of extreme precipitation events, $u$ is the threshold of precipitation amount for identifying extreme precipitation events. Further details about the EPI can be found in Pei et al., 
(2017) [39]. Supposing that the EPI $I_{t}$ depends linearly on the corresponding time $t$, the temporal trend of extreme precipitation intensity $\left(E P I_{t}\right)$ was analyzed over the period 1982-2012 using a linear regression model:

$$
E P I_{t}=\alpha+\beta \cdot T
$$

where $\alpha$ and $\beta$ represent regression coefficients in the regression model. It means that if $\beta$ is different from 0 at the 0.05 level from $t$-test $(p<0.05)$, then statistical evidence supports the existence of such a trend over that period.

\subsection{The Performance Assessment of Minimum, Mean and Maximum NDVIs for Monitoring Extreme Precipitation Events}

In the past decades, remotely sensed observation has greatly facilitated the largescale monitoring of terrestrial vegetation activity. Many vegetation indices, including NDVI, Enhanced Vegetation Index (EVI) and Soil-Adjusted Vegetation Index (SAVI), were developed to reflect the change in vegetation growth [45-47]. Despite it, the NDVI is still a good indicator for its simplicity and the suitability of long time series of datasets when dealing with large-scale vegetation activity [48]. For instance, the GIMMS AVHRR NDVI3g dataset from NOAA has advantages on capturing the vegetation activities owing to the long period it covered, as well as the dramatic improvement of data quality.

To test the response of vegetation activity to extreme daily precipitation events, mean NDVI, and two NDVI extremes (i.e., minimum and maximum NDVIs) were employed as measures of vegetation activity separately. Provided that the GIMMS AVHRR NDVI3g dataset was preprocessed using the MVC approach to mask out cloud, snow and calibration loss, minimum, mean, and maximum NDVIs were obtained by calculating the average values of the three NDVIs in the growing season year by year. A linear regression model was applied to the three NDVI indices in order to evaluate whether enhanced (or weakened) vegetation growth existed from 1982 to 2012 in the MLR-YR (Equation (5)).

To examine vegetation responses to the change in extreme precipitation events, further analyses were conducted for the three NDVI indices (i.e., minimum, mean, and maximum NDVIs), respectively. Concretely, the interannual changes of the three NDVI indices, the intensity, and the frequency of daily precipitation extremes were analyzed in the MLRYR for the period 1982-2012 using linear regression and Poisson regression analyses, respectively. Both regional totals and station-by-station analyses were applied to all the three NDVI indices, the frequency and the intensity of daily precipitation extremes.

Extreme Value Theory (EVT) was widely used for estimating extreme value changes [4]. Theoretically, vegetation extremes can be detected using the EVT if the NDVI at all locations follows same distributions. Despite it, because of the nonlinear nature of the NDVI variable and its saturation under high-vegetation cover conditions, the EVT is frequently inappropriate to capture the vegetation extremes using the NDVI as an indicator [49-51]. Instead, it is common to explore NDVI anomalies for capturing the vegetation response to extreme precipitation events [51,52]. Owing to the same mechanics of the three NDVI indices, the NDVI anomalies, as well as the standard deviation of the three NDVI indices were analyzed to evaluate their sensitivity to changes in extreme precipitation events. Furthermore, correlation analysis was conducted to elucidate the relationships among the three NDVI indices, and the intensity and frequency of extreme precipitation events. As we are more interested in the spatial coherence in the sign and the magnitude of the correlations (trends) across different stations rather than concentrating on their statistical significance, the magnitude of the trends, as well as the sign of correlation coefficients were plotted in the figures for all the stations, as discussed below. Despite this, considering the local occurrence of extreme precipitation events, we analyzed the correlations between extreme precipitation indices and different NDVIs in several hotpot stations, especially in the regions with obvious trends of extreme precipitation events. In addition, past studies showed that the distributions of terrestrial vegetation are widely influenced by total annual precipitation. To better understand the impacts of extreme precipitation events, as well as 
the performances of the three indices to represent them, correlations among annual total precipitation, precipitation amounts of extreme precipitation events and three NDVI-based indices were analyzed using the time series of observations on the total annual precipitation and NDVI from 1982 to 2012.

\section{Results}

\subsection{Changes of Annual Total Precipitation, the Frequency and the Intensity of Extreme Precipitation Events}

As shown in Figure 2, annual total precipitation showed an insignificant decreasing trend in the MLR-YR over the period 1982-2012, at a rate of $2.2 \mathrm{~mm} /$ year $(p=0.377)$. In addition, a significant increasing trend of the extreme precipitation intensity was found, at a rate of $0.169 \mathrm{~mm} /$ day /year $(p=0.045)$. As to the extreme precipitation frequency, a slightly increasing trend of 0.004 day / year was found in past decades, albeit not significant $(p=0.481)$. Furthermore, similar changes were found between the intensity and the frequency of extreme precipitation events from 1982 to 2012. A significant positive correlation existed between the extreme precipitation intensity and the extreme precipitation frequency $(\mathrm{R}=0.562 ; n=31 ; p=0.001)$. In particular, relatively severe extreme precipitation events were found in the years 1983-1984, 1991, 1998, and 2010. Meanwhile, a frequent occurrence of extreme precipitation events was also observed in the same periods. Such phenomena could be attributed to strong El Niño events during those periods.

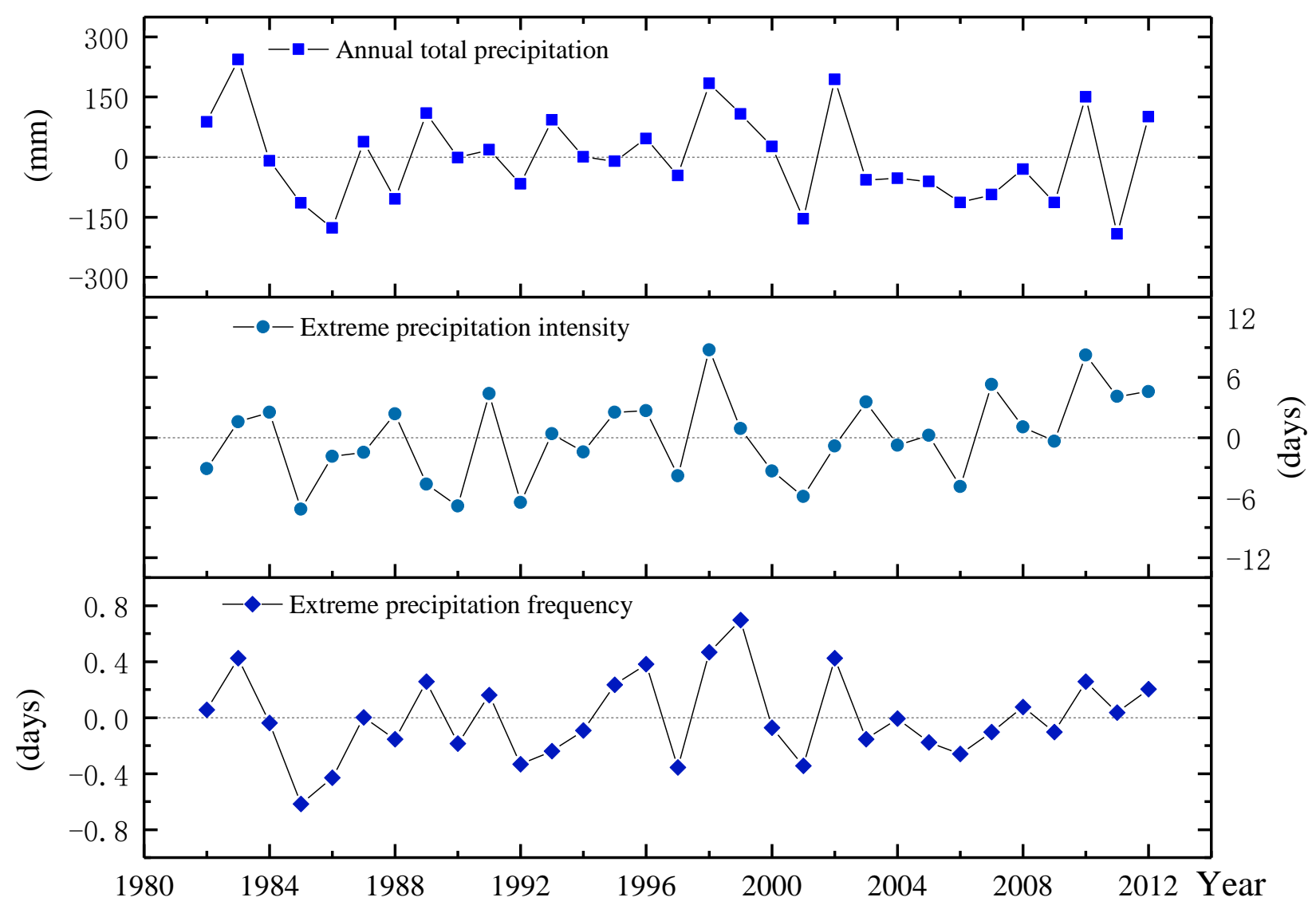

Figure 2. Temporal variations in the intensity and the frequency of extreme precipitation events in the MLR-YR from 1982 to 2012.

Besides temporal variations, the changes in annual total precipitation, extreme precipitation intensity, and extreme precipitation frequency were also spatially examined in the MLR-YR from 1982 to 2012. As shown in Figure 3a, annual total precipitation revealed a decreasing trend in past decades throughout most of the MLR-YR. In contrary, it showed 
increasing trends in several stations, including Xixia station, Nanyang station, Ankang station in the northwestern MLR-YR, and most of the stations within Jiangxi Province in the southeastern regions. In addition, extreme precipitation intensity showed an overall enhanced trend in the MLR-YR in the past decades. However, weakened extreme precipitation intensity could also be observed locally. For instance, the stations with the weakened extreme precipitation events are mainly distributed around the Hanjiang River Basin, the Dongting-Changjiang, and the Poyang-Changjiang regions (Figure 3b). In conjunction with the extreme precipitation intensity, it revealed an overall increased occurrence of extreme precipitation events in past decades in the MLR-YR (Figure 3c). Particularly, a remarkable increase in the extreme precipitation events was found in the Hanjiang River Basin in past decades, especially the regions around the Wanyuan station. On the contrary, extreme precipitation frequency severely weakened in the regions around the JialingjiangMinjiang region in the northwestern MLR-YR, the Danjiangkou-Hanjiang region to the southern Sichuan Basin and the Xiangjiang River basin. In addition, obvious concurrent enhancements in the intensity and the frequency of extreme precipitation events were also found around the Hanjiang River Basin and the southern MLR-YR, including Wanyuan, Chenzhou, Daoxian, and Ganzhou stations.
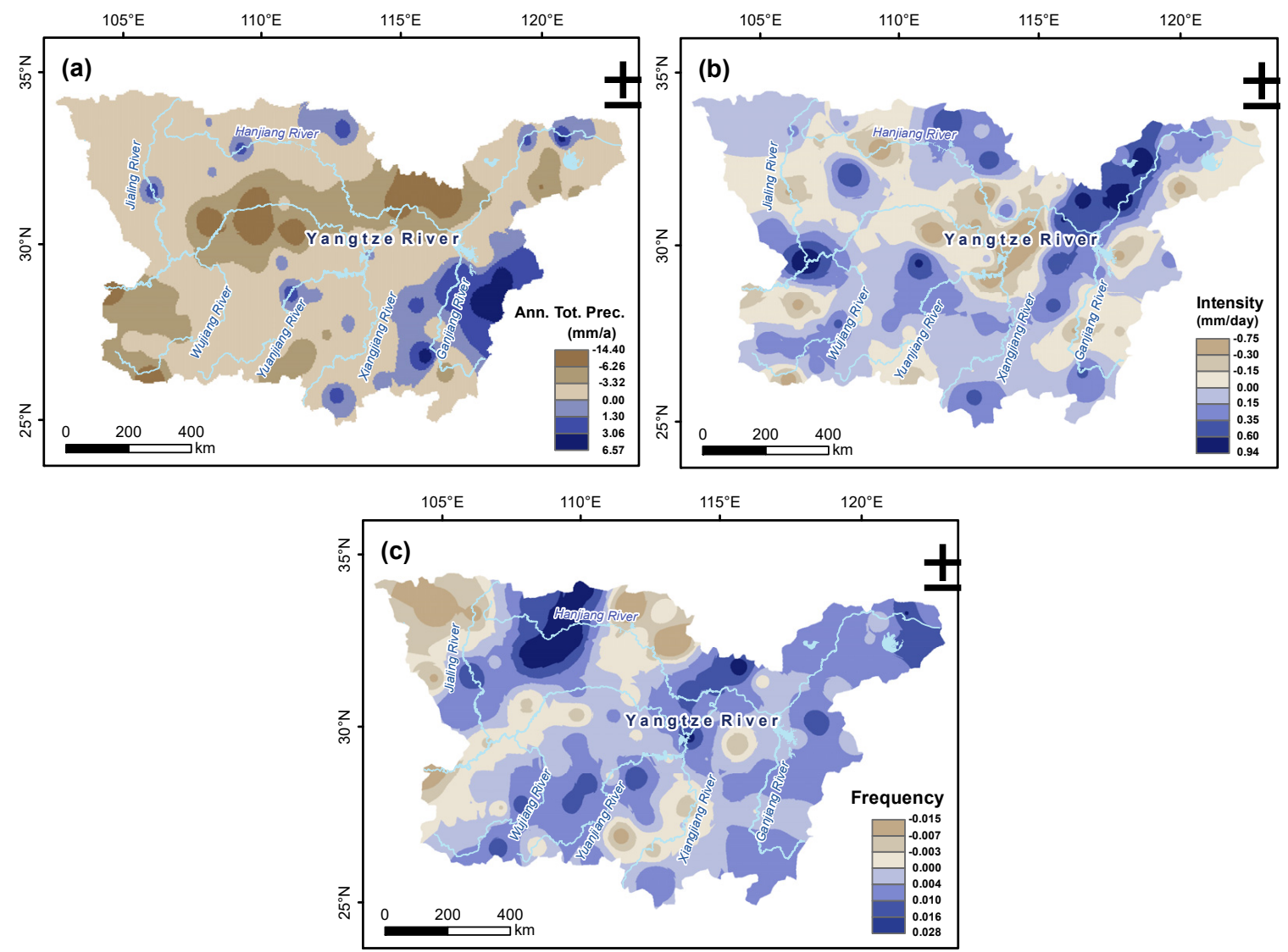

Figure 3. Spatial distribution of temporal trends in (a) annual total precipitation, (b) extreme precipitation intensity and (c) extreme precipitation frequency in the MLR-YR from 1982 to 2012.

\subsection{Changes of Three NDVI-Based Indices}

By using minimum, mean, and maximum NDVIs in the growing season as proxies, Figure 4 shows interannual anomalies of vegetation activity in the MLR-YR in the past decades. Concretely, the three NDVI indices showed a fluctuation from 1982 to 2012. That is, the maximum NDVI varied between 0.73 and 0.79 in past decades, with the mean NDVI ranging between 0.52 to 0.59 . In addition, the minimum NDVI was found to vary between 0.25 to 0.31 . As shown in Figure 4, similar changes were found among the three NDVI 
indices. For instances, a significant positive correlation was found between the maximum and the mean NDVI ( $\mathrm{R}=0.736 ; n=31 ; p=0.000)$. In particular, relatively low NDVI was found for the maximum and the mean NDVI in the years 1984, 1988, 1993, 1999, and 2005. In addition, the correlation between the minimum and the mean NDVIs was also significant $(\mathrm{R}=0.541 ; n=31 ; p=0.002)$. The minimum and mean NDVIs were relatively small in the years 1984, 1988, 1993, 1996, 1999, and 2009. In addition, all the three NDVI indices revealed slight increasing trends, at a rate of 0.01 per decade $(p=0-0.002)$.

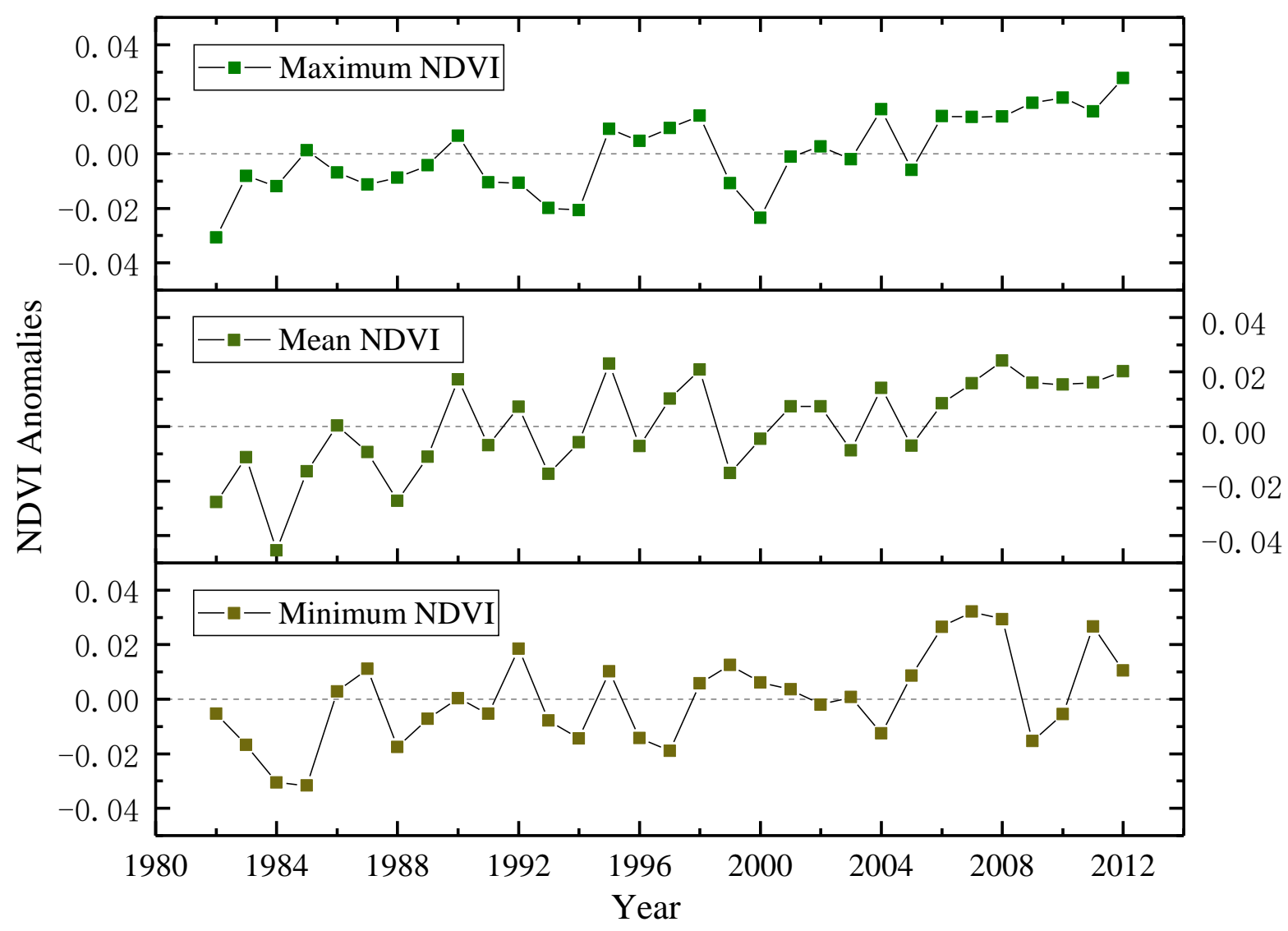

Figure 4. Anomalies of minimum, mean and maximum NDVIs in the MLR-YR from 1982 to 2012.

We further explored the temporal trends and the standard deviation of the three NDVI indices in the MLR-YR from 1982 to 2012. Similar patterns were found between the standard deviation of the minimum, the mean and the maximum NDVIs, and their temporal trends (not showed here), respectively. Taking the standard deviation analysis as an instance, we analyzed the differences among all the three NDVI indices. Concretely, the standard deviation of the minimum, mean, and maximum NDVIs ranged from 0 to $0.129,0$ to 0.177 , and 0 to 0.250 , respectively. As shown in Figure $5 \mathrm{a}-\mathrm{c}$, the standard deviation of the three NDVI indices was relatively small in the southwestern MLR-YR over the period 1982-2012. However, obvious differences were found in the regions where a large standard deviation exists. For instances, it revealed a large standard deviation of the mean NDVI in the northwestern MLR-YR, including the Hanjiang River Basin. In contrary, the standard deviation of the minimum and maximum NDVIs was relatively large in northeastern MLR-YR. As to the maximum NDVI, a large standard deviation was mainly distributed in Danjiangkou-Hanjiang, Poyang-Yangtze, Dongting-Yangtze, and Taihu-Chaohu-Yangtze regions. 


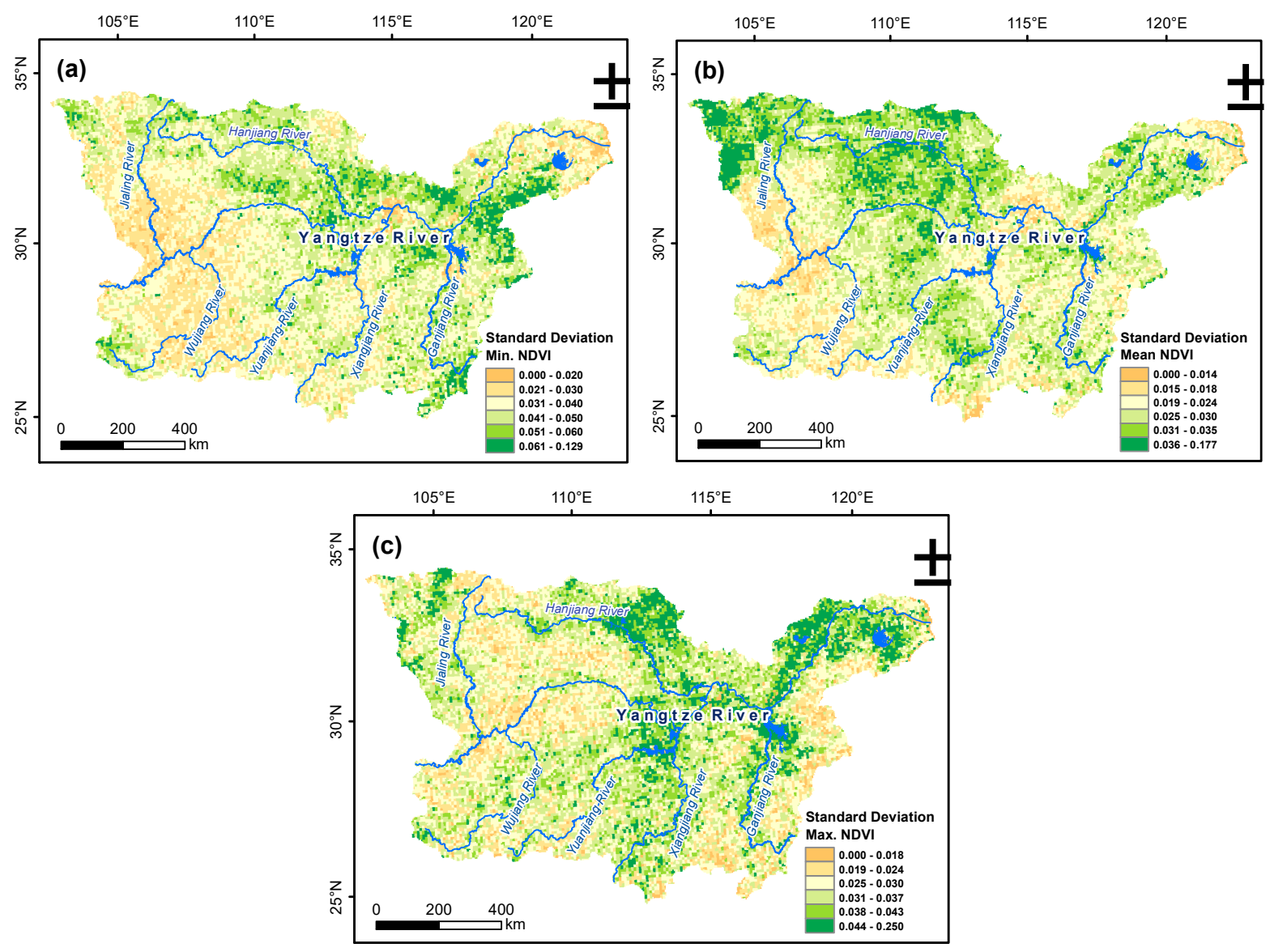

Figure 5. Standard deviation of three NDVI indices in the MLR-YR from 1982 to 2012: (a) minimum NDVI, (b) mean NDVI and (c) maximum NDVI.

4.3. The Correlations between the Frequency, the Intensity of Extreme Precipitation Events and Three NDVI-Based Indices

4.3.1. Meteorological-Station-Based Analysis on the Correlations

The impacts of extreme precipitation events on vegetation activity were analyzed using minimum, mean, and maximum NDVIs as proxies, respectively. We found that the correlation was relatively small between the three NDVI indices and the intensity, the frequency of extreme precipitation events. As a whole, the correlation coefficients between extreme precipitation intensity and the minimum, mean, and maximum NDVIs is 0.338 , 0.066 , and 0.127 , despite not significant. According to the station-by-station analysis, both positive and negative correlations were found between extreme precipitation intensity and all the three NDVI indices in the MLR-YR. Furthermore, the correlation coefficients between maximum NDVI and extreme precipitation intensity ranged between -0.51 and 0.45 among the 97 stations. Similar phenomena were found between extreme precipitation intensity and mean NDVI, with correlation coefficients ranged between -0.55 and 0.60 . For the minimum NDVI, the correlation coefficients varied between -0.37 and 0.42 , which were relatively small in comparison to the other two NDVI indices.

For the extreme precipitation frequency, similar correlations were found for all the three NDVI indices. Despite this, the correlation coefficients were much smaller than that of the extreme precipitation intensity. Take the MLR-YR as a whole, the correlation coefficients between extreme precipitation frequency and the maximum, the mean, the minimum NDVI are $0.11,0.05$, and 0.10 , respectively. By stations, the correlation coefficients between extreme precipitation frequency and the maximum, mean, minimum NDVI ranged between -0.41 and $0.41,-0.29$ and $0.52,-0.43$ and 0.41 , respectively. To elucidate the spatial details of the positive and the negative correlations, spatial heterogeneity of the 
correlations was further analyzed to match the changes of extreme precipitation events with that of the vegetation activity in the MLR-YR.

\subsubsection{Spatial Heterogeneity of the Correlations in the MLR-YR}

It is important to combine extreme precipitation intensity and extreme precipitation frequency when analyzing the effect of extreme precipitation events on vegetation activity [53]. Figure $6 \mathrm{a}-\mathrm{f}$ show the spatial distribution of the correlations between extreme precipitation intensity, frequency, and the three NDVI indices (i.e., minimum, mean, and maximum NDVIs) in the MLR-YR, respectively. We found that the correlations tended to change with the relative severity of the extreme precipitation events concerning the intensity and the frequency. Obvious heterogeneities were found in the regions with different trends of extreme precipitation events, including decreased daily extreme precipitation, enhanced daily extreme precipitation, and no obvious trend of daily extreme precipitation.
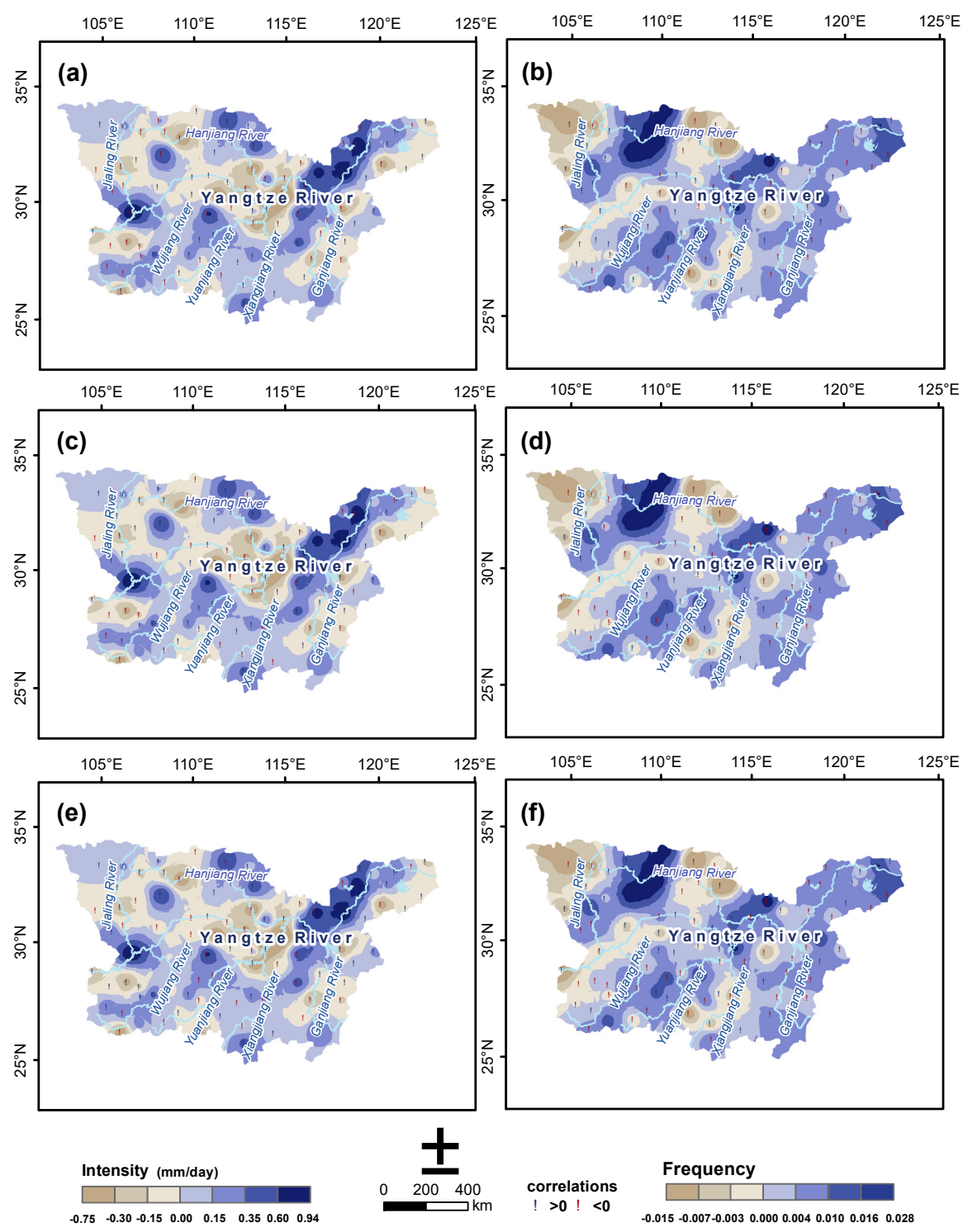

Figure 6. Spatial distribution of the correlations between: (a) maximum NDVI and extreme precipitation intensity; (b) maximum NDVI and extreme precipitation frequency; (c) mean NDVI and extreme precipitation intensity; (d) mean NDVI and extreme precipitation frequency; (e) minimum NDVI and extreme precipitation intensity; (f) minimum NDVI and extreme precipitation frequency. 
In the regions with severely weakened intensity and increased frequency of precipitation extremes, negative correlations were found in the croplands between extreme precipitation intensity and all the three NDVI indices in the MLR-YR during 1982-2012. This is particularly obvious in northwestern MLR-YR, around the Dongting-Yangtze regions, and so on. Positive correlations were also found between extreme precipitation intensity and all the three NDVI indices in the regions with enhanced extreme precipitation intensity but decreased extreme precipitation frequency (e.g., in the Danjiangkou-Hanjiang region) (Figure 6a,c,e). In addition, negative correlations were also found between extreme precipitation frequency and the three NDVI indices when extreme precipitation frequency decreased (Figure $6 \mathrm{~b}, \mathrm{~d}, \mathrm{f})$. These results indicate that decreased extreme precipitation events frequently enhanced vegetation growth in the MLR-YR. The findings are partly consistent with the case studies of the Poyang Lake basin by Tan et al. (2015) [18]. This phenomenon could be attributed to the decreased annual total precipitation and the water supply from extreme precipitation events (Figure 3a). Namely, rich water from extreme precipitation events might contribute to plant growth when extreme precipitation events were not very severe (e.g., only the frequency or the intensity of the extreme precipitation events weakened).

Furthermore, negative correlations between extreme precipitation intensity and maximum NDVI also exist in the stations, including Shapingba, Wanyuan, Shangzhi, and some others around the Poyang-Yangtze region when extreme precipitation intensity revealed severely enhanced trends (Figure 6a). In contrary, positive correlations were found in such stations for the mean and the minimum NDVI indices (Figure $6 c, e$ ). This phenomenon could be associated with the extreme precipitation constraint on favorable weather to vegetation growth. However, such rich water might be beneficial to plant growth and thus improved the mean and the minimum NDVI. Except for the severity of extreme precipitation events, many other factors, including geographic location, catchment size, and duration of extreme precipitation events, may account for such phenomena as well $[4,54]$.

When changes in the intensity/frequency of extreme precipitation events were relatively small or even no obvious trends, both positive and negative correlations were found between the intensity and frequency of extreme precipitation events and the three NDVI indices in the regions.

As mentioned previously, obvious heterogeneities of the correlations were found locally, especially in the regions with different trends of extreme precipitation events: northwestern MLR-YR, Danjiangkou-Hanjiang region, Poyang-Yangtze region, Southern MLR-YR, Dongting-Yangtze region and Chaohu-Yangtze region. Taking several hotspot stations in such regions as instances, we further compared the correlations between extreme precipitation intensity $\left(\mathrm{R}_{\mathrm{EPI}}\right)$, extreme precipitation frequency $\left(\mathrm{R}_{\mathrm{EPF}}\right)$, and the three NDVIbased indices (Table 1). For instance, when extreme precipitation intensity was decreasing and extreme precipitation frequency was increasing in Ankang and Jiayu stations, negative correlations were found between extreme precipitation intensity and maximum NDVI (i.e., $\mathrm{R}=-0.52, p=0.00$ and $\mathrm{R}=-0.35, p=0.05$, respectively). In addition, when extreme precipitation intensity was increasing and extreme precipitation frequency was decreasing or unchanged in the Xixia and Yingshan stations, positive correlations were found between extreme precipitation intensity and maximum NDVI (i.e., $\mathrm{R}=0.43, p=0.02$ and $\mathrm{R}=0.29$, $p=0.12$, respectively). However, when both the intensity and the frequency of extreme precipitation events were increasing in Nancang station, a negative correlation was found between extreme precipitation intensity and maximum NDVI (i.e., $\mathrm{R}=0.40, p=0.03$ ). On the contrary, the correlations between extreme precipitation intensity and minimum NDVI were not significant at most of the stations. 
Table 1. The correlations between extreme precipitation indices and different NDVIs in several hotpot stations.

\begin{tabular}{|c|c|c|c|c|c|c|c|c|c|}
\hline \multirow{2}{*}{ Regions } & \multirow{2}{*}{ Stations } & \multicolumn{2}{|c|}{$\begin{array}{c}\text { Extreme Precipitation } \\
\text { Events }\end{array}$} & \multicolumn{2}{|c|}{ Maximum NDVI } & \multicolumn{2}{|c|}{ Minimum NDVI } & \multicolumn{2}{|c|}{ Mean NDVI } \\
\hline & & EPI & EPF & $\mathbf{R}_{\mathrm{EPI}}$ & $\mathbf{R}_{\mathrm{EPF}}$ & $\mathbf{R}_{\mathrm{EPI}}$ & $\mathbf{R}_{\mathrm{EPF}}$ & $\mathbf{R}_{\text {EPI }}$ & $\mathbf{R}_{\mathrm{EPF}}$ \\
\hline Northwestern MLR-YR & Ankang & Decreasing & Increasing & $\begin{array}{c}\mathrm{R}=-0.52 \\
p=0.00\end{array}$ & $\begin{array}{l}\mathrm{R}=0.39 \\
p=0.03\end{array}$ & $\begin{aligned} \mathrm{R} & =-0.11 \\
p & =0.56\end{aligned}$ & $\begin{array}{l}\mathrm{R}=0.56 \\
p=0.05\end{array}$ & $\begin{array}{c}\mathrm{R}=-0.53 \\
p=0.00\end{array}$ & $\begin{array}{l}\mathrm{R}=0.52 \\
p=0.00\end{array}$ \\
\hline $\begin{array}{l}\text { Danjiangkou-Hanjiang } \\
\text { region }\end{array}$ & Xixia & Increasing & Decreasing & $\begin{array}{l}\mathrm{R}=0.43 \\
p=0.02\end{array}$ & $\begin{aligned} \mathrm{R} & =-0.34 \\
p & =0.06\end{aligned}$ & $\begin{aligned} \mathrm{R} & =-0.01 \\
p & =0.96\end{aligned}$ & $\begin{aligned} \mathrm{R} & =-0.18 \\
p & =0.34\end{aligned}$ & $\begin{array}{l}\mathrm{R}=0.18 \\
p=0.33\end{array}$ & $\begin{array}{c}\mathrm{R}=-0.14 \\
p=0.46\end{array}$ \\
\hline Poyang-Yangtze region & Nancang & Increasing & Increasing & $\begin{array}{c}\mathrm{R}=-0.40 \\
p=0.03\end{array}$ & $\begin{array}{l}\mathrm{R}=0.13 \\
p=0.50\end{array}$ & $\begin{array}{c}\mathrm{R}=-0.05 \\
p=0.78\end{array}$ & $\begin{array}{c}\mathrm{R}=-0.19 \\
p=0.30\end{array}$ & $\begin{array}{c}\mathrm{R}=-0.38 \\
p=0.03\end{array}$ & $\begin{aligned} \mathrm{R} & =-0.05 \\
p & =0.80\end{aligned}$ \\
\hline Dongting-Yangtze region & Jiayu & Decreasing & Increasing & $\begin{aligned} \mathrm{R} & =-0.35 \\
p & =0.05\end{aligned}$ & $\begin{aligned} \mathrm{R} & =-0.06 \\
p & =0.75\end{aligned}$ & $\begin{array}{l}\mathrm{R}=0.04 \\
p=0.85\end{array}$ & $\begin{array}{l}\mathrm{R}=0.22 \\
p=0.23\end{array}$ & $\begin{array}{c}\mathrm{R}=-0.16 \\
p=0.38\end{array}$ & $\begin{aligned} \mathrm{R} & =-0.02 \\
p & =0.92\end{aligned}$ \\
\hline Chaohu-Yangtze region & Yingshan & Increasing & Unchanged & $\begin{array}{l}\mathrm{R}=0.29 \\
p=0.12\end{array}$ & $\begin{array}{c}\mathrm{R}=-0.14 \\
p=0.47\end{array}$ & $\begin{array}{c}\mathrm{R}=-0.02 \\
p=0.93\end{array}$ & $\begin{array}{l}\mathrm{R}=0.11 \\
p=0.57\end{array}$ & $\begin{array}{l}\mathrm{R}=0.27 \\
p=0.14\end{array}$ & $\begin{array}{c}\mathrm{R}=-0.04 \\
p=0.83\end{array}$ \\
\hline
\end{tabular}

4.3.3. Correlations between Annual Total Precipitation, Precipitation Amount of Extreme Precipitation Events and NDVI

According to the results, precipitation amounts of extreme precipitation events in the MLR-YR contribute to 5-13\% of annual total precipitation. Despite this, a significant correlation was found between extreme precipitation amounts and maximum NDVI $(\mathrm{R}=-0.238$; $n=97 ; p=0.020$ ) (Table 2).

Table 2. Correlations between annual total precipitation, precipitation amount of extreme precipitation events and three NDVI-based indices.

\begin{tabular}{ccccccc}
\hline & \multicolumn{2}{c}{ Maximum NDVI } & \multicolumn{2}{c}{ Mean NDVI } & \multicolumn{2}{c}{ Minimum NDVI } \\
\cline { 2 - 7 } & $\mathbf{R}$ & $\boldsymbol{p}$ & $\mathbf{R}$ & $\boldsymbol{p}$ & $\mathbf{R}$ & $\boldsymbol{p}$ \\
\hline Annual total precipitation & -0.067 & 0.518 & 0.061 & 0.556 & 0.253 & 0.013 \\
Extreme precipitation amount & -0.238 & 0.020 & -0.225 & 0.028 & -0.110 & 0.290 \\
\hline
\end{tabular}

\section{Discussions}

Using the MLR-YR in subtropical monsoon climatic zone as an instance, we found that annual changes in extreme precipitation intensity were overall similar to that of extreme precipitation frequency over the period of 1982-2012. Namely, both the intensity and the frequency of extreme precipitation events revealed strengthened trends from 1982 to 2012. In contrast to temporal changes of extreme precipitation events, obvious spatial discrepancies were found among intensity, frequency of extreme precipitation events, and annual total precipitation. Past works found that extreme precipitation events correlate with minimum, mean, and maximum NDVIs in different contexts [21-23]. According to our results, both positive and negative correlations could be found between extreme precipitation events and all the three NDVI indices. However, spatial distributions of the temporal trend of annual total precipitation were found to significantly differ with that of the three NDVI indices (Figures $3 a$ and 5). The results are consistent with the findings of Guo et al. (2013) [55], which pointed out that mean precipitation cannot reflect changes in the extreme precipitation, and thus on vegetation extremes. The positive or negative sign of the correlation was probably associated with the opposite changes of the intensity and the frequency of extreme precipitation events. That is, vegetation activity can be strengthened when extreme precipitation events become eased (e.g., weakened extreme precipitation intensity but enhanced extreme precipitation frequency, or reversed). In contrast to mean and minimum NDVIs, negative correlations between extreme precipitation intensity and the maximum NDVI also exists in some stations when extreme precipitation intensity revealed a severely enhanced trend. This phenomenon can explain that enhanced extreme precipitation intensity might threaten plant growth and thus reduce the maximum NDVI in the MLR-YR. Despite this, rich water from the enhanced extreme precipitation events might contribute to plant growth and thus improve the mean and minimum NDVIs.

Furthermore, we found that the spatial patterns of extreme precipitation intensity were similar than that of the changes in vegetation activity in the MLR-YR, which was 
analyzed using maximum and minimum NDVIs, especially the maximum NDVI. Besides this, the performance of the maximum NDVI on capturing extreme precipitation events can also be explained using standard deviation analysis of the NDVI changes in past decades. As illustrated in the aforementioned sections, it shows a large standard deviation of the maximum NDVI in the regions with severely extreme precipitation changes (e.g., enhanced or weakened intensity of extreme precipitation events). A consistency was also found between spatial patterns of extreme precipitation intensity and that of the standard deviation of the maximum NDVI. Furthermore, the standard deviation of the maximum, mean and minimum NDVIs were $0.032,0.026$, and 0.039 , respectively. If there were no extreme precipitation events, it would have been unlikely that the standard deviation of maximum and minimum NDVIs are greater than the mean NDVI. Namely, in comparison with mean NDVI, maximum and minimum NDVIs were more effective in reflecting the change in extreme precipitation events.

The performance can be explained using not only the standard deviation of the NDVIs, but also the correlations between extreme precipitation events and the three NDVI indices. Fernandez-Carrillo et al. (2019) pointed out a positive correlation between accumulated rainfall and minimum NDVI in the Donana National Park in the Iberian Peninsula [23]. Furthermore, a negative correlation was found between accumulated rainfall and maximum NDVI as well. They inferred that such a negative correlation was caused by flooding events. However, complex correlations were found in the MLR-YR when it referred to extreme precipitation events. In this paper, the correlations were further analyzed by combining the intensity and the frequency of extreme precipitation events as a whole. In particular, our results showed that correlation coefficients between the maximum NDVI and the intensity of extreme precipitation events were relatively larger than that of the minimum NDVI.

In addition, it is known that NDVI is frequently influenced by changing precipitation patterns [56]. In this paper, the contribution of precipitation amounts of extreme precipitation events to annual total precipitation is smaller than the results of Almazroui (2020) [57] and Almazroui and Saeed (2020) [58]. This phenomenon can be associated with the wide distribution of typical subtropical monsoon climate in the MLR-YR. In addition, it can be caused by the fact that we only include rainy days to obtain the precipitation percentiles in this study. Despite it, the correlations between extreme precipitation amounts and maximum NDVI are larger than that of the minimum and mean NDVIs. Thus, the maximum NDVI is more suited than the other two NDVI indices to capture the response of vegetation activity to extreme precipitation events in typical subtropical monsoon climatic zones, such as the MLR-YR region. These results could be associated with the uncertainty when compiling the minimum NDVI, based on the GIMMS NDVI3g dataset, which employed the MVC to mask out atmospheric effects [28,59].

\section{Conclusions}

In this paper, we analyzed the application of minimum, mean, and maximum NDVIs on detecting extreme precipitation changes using the MLR-YR as a case study. Key findings are drawn as follows: (1) both similar temporal changes and obvious spatial discrepancy were found between extreme precipitation intensity and extreme precipitation frequency from 1982 to 2012 in the MLR-YR, indicating an increasing trend of extreme precipitation events; (2) a consistency was found between changes in extreme precipitation intensity and changes in the standard deviation of the maximum NDVI; (3) the correlation coefficients between maximum NDVI and the intensity of extreme precipitation events were larger than that of the minimum NDVI; and (4) in comparison to the mean and minimum NDVIs, our results indicate that maximum NDVI was more suited to capture the response of vegetation activity to the change in extreme precipitation events.

This study was conducted by assuming that the probabilistic characteristics of climate variables do not change over time. However, it is established that this assumption of stationarity can no longer hold because of climate change and anthropogenic factors [60]. 
Therefore, it is essential to consider the nonstationary of precipitation extremes in future studies. In addition, by using the MLR-YR in subtropical monsoon climatic zone as an instance, we found that maximum NDVI is more suited to capture the response of vegetation activity to extreme precipitation events in comparison with the minimum NDVI and mean NDVI. Despite it, characteristics of extreme precipitation events can be changed for complex climate conditions, topography and vegetation types. Further studies should be conducted in different climatic zones in order to validate the effects of maximum NDVI.

Author Contributions: F.P. and Y.X. contributed to research design, data analysis, interpretation of results, and draft manuscript preparation; Y.Z. and F.P. contributed to the data collection; Y.Z. performed experiments and computational analysis; F.P. and Y.Z. drafted the paper, and all authors contributed to the final draft of the manuscript. All authors have read and agreed to the published version of the manuscript.

Funding: This research was funded by Qinglan Project of Jiangsu Province in China, the Project of Philosophy and Social Science Re-search in Colleges and Universities in Jiangsu Province (Grant No. 2019SJA0915), and the Priority Academic Program Development of Jiangsu Higher Education Institutions.

Institutional Review Board Statement: Not applicable.

Informed Consent Statement: Not applicable.

Data Availability Statement: The datasets in this study are available within this article. The data which were derived from the original datasets but not aforementioned are available upon requests.

Acknowledgments: This study was supported by Qinglan Project of Jiangsu Province in China, the Project of Philosophy and Social Science Research in Colleges and Universities in Jiangsu Province (Grant No. 2019SJA0915), and the Priority Academic Program Development of Jiangsu Higher Education Institutions. Special thanks are given to the two anonymous reviewers for their insightful comments and suggestions.

Conflicts of Interest: The authors declare no conflict of interest.

\section{References}

1. IPCC. Summary for Policymakers. In Climate Change and Land: An IPCC Special Report on Climate Change, Desertification, Land Degradation, Sustainable Land Management, Food Security, and Greenhouse Gas Fluxes in Terrestrial Ecosystems; Shukla, P.R., Skea, J., Calvo Buendia, E., Masson-Delmotte, V., Pörtner, H.-O., Roberts, D.C., Zhai, P., Slade, R., Connors, S., van Diemen, R., et al., Eds.; Cambridge University Press: Cambridge, UK, 2019.

2. Cai, W.; Borlace, S.; Lengaigne, M.; van Rensch, P.; Collins, M.; Vecchi, G.; Timmermann, A.; Santoso, A.; McPhaden, M.J.; Wu, L. Increasing frequency of extreme El Niño events due to greenhouse warming. Nat. Clim. Chang. 2014, 4, 111-116. [CrossRef]

3. Kendon, E.J.; Stratton, R.A.; Tucker, S.; Marsham, J.H.; Berthou, S.; Rowell, D.P.; Senior, C.A. Enhanced future changes in wet and dry extremes over Africa at convection-permitting scale. Nat. Commun. 2019, 10, 1-14. [CrossRef]

4. IPCC. Managing the Risks of Extreme Events and Disasters to Advance Climate Change Adaptation: Special Report of the Intergovernmental Panel on Climate Change; Cambridge University Press: Cambridge, UK, 2012.

5. Coronese, M.; Lamperti, F.; Keller, K.; Chiaromonte, F.; Roventini, A. Evidence for sharp increase in the economic damages of extreme natural disasters. Proc. Natl. Acad. Sci. USA 2019, 116, 21450. [CrossRef]

6. Davis, C.J.; Hanna, E.G. Seasonal temperature and rainfall extremes 1911-2017 for Northern Australian population centres: Challenges for human activity. Reg. Environ. Chang. 2020, 20, 128. [CrossRef]

7. John, R.; Chen, J.; Ou-Yang, Z.-T.; Xiao, J.; Becker, R.; Samanta, A.; Ganguly, S.; Yuan, W.; Batkhishig, O. Vegetation response to extreme climate events on the Mongolian Plateau from 2000 to 2010. Environ. Res. Lett. 2013, 8, 035033. [CrossRef]

8. Santo, F.E.; Ramos, A.M.; de Lima, M.I.P.; Trigo, R.M. Seasonal changes in daily precipitation extremes in mainland Portugal from 1941 to 2007. Reg. Environ. Chang. 2014, 14, 1765-1788. [CrossRef]

9. Sepúlveda, M.; Bown, H.E.; Miranda, M.D.; Fernández, B. Impact of rainfall frequency and intensity on inter-and intra-annual satellite-derived EVI vegetation productivity of an Acacia caven shrubland community in Central Chile. Plant Ecol. 2018, 219, 1209-1223. [CrossRef]

10. Kogan, F.N. Remote sensing of weather impacts on vegetation in non-homogeneous areas. Int. J. Remote Sens. 1990, 11, 1405-1419. [CrossRef]

11. Brun, J.; Barros, A.P. Vegetation activity monitoring as an indicator of eco-hydrological impacts of extreme events in the southeastern USA. Int. J. Remote Sens. 2013, 34, 519-544. [CrossRef]

12. Nagai, S.; Nasahara, K.N.; Muraoka, H.; Akiyama, T.; Tsuchida, S. Field experiments to test the use of the normalized-difference vegetation index for phenology detection. Agric. For. Meteorol. 2010, 150, 152-160. [CrossRef] 
13. Kogan, F.N. Application of vegetation index and brightness temperature for drought detection. Adv. Space Res. 1995, 15, 91-100. [CrossRef]

14. Unganai, L.S.; Kogan, F.N. Drought monitoring and corn yield estimation in Southern Africa from AVHRR data. Remote Sens. Environ. 1998, 63, 219-232. [CrossRef]

15. Kogan, F.; Guo, W. Early detection and monitoring droughts from NOAA environmental satellites. In Use of Satellite and In-Situ Data to Improve Sustainability; Springer: Dordrecht, The Netherlands, 2011; pp. 11-18.

16. Pei, F.; Wu, C.; Liu, X.; Li, X.; Yang, K.; Zhou, Y.; Wang, K.; Xu, L.; Xia, G. Monitoring the vegetation activity in China using vegetation health indices. Agric. For. Meteorol. 2018, 248, 215-227. [CrossRef]

17. Pei, F.; Li, X.; Liu, X.; Lao, C. Assessing the impacts of droughts on net primary productivity in China. J. Environ. Manag. 2013, 114, 362-371. [CrossRef] [PubMed]

18. Tan, Z.; Tao, H.; Jiang, J.; Zhang, Q. Influences of climate extremes on NDVI (normalized difference vegetation index) in the Poyang Lake Basin, China. Wetlands 2015, 35, 1033-1042. [CrossRef]

19. Cui, L.; Wang, L.; Qu, S.; Singh, R.P.; Lai, Z.; Yao, R. Spatiotemporal extremes of temperature and precipitation during 1960-2015 in the Yangtze River Basin (China) and impacts on vegetation dynamics. Theor. Appl. Climatol. 2019, 136, 675-692. [CrossRef]

20. Kogan, F.; Gitelson, A.; Zakarin, E.; Spivak, L.; Lebed, L. AVHRR-based spectral vegetation index for quantitative assessment of vegetation state and productivity. Photogramm. Eng. Remote Sens. 2003, 69, 899-906. [CrossRef]

21. Potter, C.S.; Brooks, V. Global analysis of empirical relations between annual climate and seasonality of NDVI. Int. J. Remote Sens. 1998, 19, 2921-2948. [CrossRef]

22. Chamaillé-Jammes, S.; Fritz, H. Precipitation-NDVI relationships in eastern and southern African savannas vary along a precipitation gradient. Int. J. Remote Sens. 2009, 30, 3409-3422. [CrossRef]

23. Fernandez-Carrillo, A.; Sanchez-Rodriguez, E.; Rodriguez-Galiano, V.F. Characterising marshland temporal dynamics using remote sensing: The case of Bolboschoenetum maritimi in Doñana national park. Appl. Geogr. 2019, 112, 102094. [CrossRef]

24. Zong, Y.; Chen, X. The 1998 flood on the Yangtze, China. Nat. Hazards 2000, 22, 165-184. [CrossRef]

25. Shen, H.; Kuang, Y.; Zi, L. Genesis of 2010 storm-flood in Yangtze River Basin and its comparison with 1998 flood. Yangtze River 2011, 42, 11-14.

26. China Meteorological Administration (CMA). Surface Meteorological Observation Standards; China Meteorological Press: Beijing, China, 1979.

27. Tucker, C.J.; Pinzon, J.E.; Brown, M.E.; Slayback, D.A.; Pak, E.W.; Mahoney, R.; Vermote, E.F.; El Saleous, N. An extended AVHRR 8-km NDVI dataset compatible with MODIS and SPOT vegetation NDVI data. Int. J. Remote Sens. 2005, 26, 4485-4498. [CrossRef]

28. Pinzon, J.E.; Tucker, C.J. A non-stationary 1981-2012 AVHRR NDVI3g time series. Remote Sens. 2014, 6, 6929-6960. [CrossRef]

29. Fisher, R.A.; Tippett, L.H.C. Limiting forms of the frequency distribution of the largest or smallest member of a sample. In Mathematical Proceedings of the Cambridge Philosophical Society; Cambridge University Press: Cambridge, UK, 1928; pp. 180-190.

30. Todorovic, P.; Zelenhasic, E. A stochastic model for flood analysis. Water Resour. Res. 1970, 6, 1641-1648. [CrossRef]

31. Coles, S.; Heffernan, J.; Tawn, J. Dependence measures for extreme value analyses. Extremes 1999, 2, 339-365. [CrossRef]

32. Faranda, D.; Lucarini, V.; Turchetti, G.; Vaienti, S. Numerical convergence of the block-maxima approach to the generalized extreme value distribution. J. Stat. Phys. 2011, 145, 1156-1180. [CrossRef]

33. Lazoglou, G.; Anagnostopoulou, C.; Tolika, K.; Kolyva-Machera, F. A review of statistical methods to analyze extreme precipitation and temperature events in the Mediterranean region. Theor. Appl. Climatol. 2019, 136, 99-117. [CrossRef]

34. Pandey, M.D.; van Gelder, P.; Vrijling, J.K. The estimation of extreme quantiles of wind velocity using L-moments in the peaks-over-threshold approach. Struct. Saf. 2001, 23, 179-192. [CrossRef]

35. Thiombiano, A.N.; El Adlouni, S.; St-Hilaire, A.; Ouarda, T.B.; El-Jabi, N. Nonstationary frequency analysis of extreme daily precipitation amounts in Southeastern Canada using a peaks-over-threshold approach. Theor. Appl. Climatol. 2017, 129, 413-426. [CrossRef]

36. Caissie, D.; Ashkar, F.; El-Jabi, N. Analysis of air/river maximum daily temperature characteristics using the peaks over threshold approach. Ecohydrology 2020, 13, e2176. [CrossRef]

37. Coles, S.; Bawa, J.; Trenner, L.; Dorazio, P. An Introduction to Statistical Modeling of Extreme Values; Springer: London, UK, 2001.

38. Pickands, J., III. Statistical inference using extreme order statistics. Ann. Stat. 1975, 3, 119-131.

39. Pei, F.; Wu, C.; Qu, A.; Xia, Y.; Wang, K.; Zhou, Y. Changes in extreme precipitation: A case study in the middle and lower reaches of the Yangtze River in China. Water 2017, 9, 943. [CrossRef]

40. Saeed, S.; Brisson, E.; Demuzere, M.; Tabari, H.; Willems, P.; Lipzig, N.V. Multidecadal convection permitting climate simulations over Belgium: Sensitivity of future precipitation extremes. Atmos. Sci. Lett. 2017, 18, 29-36. [CrossRef]

41. Karl, T.R.; Nicholls, N.; Ghazi, A. Clivar/GCOS/WMO workshop on indices and indicators for climate extremes workshop summary. In Weather and Climate Extremes; Springer: London, UK, 1999; pp. 3-7.

42. Kim, J.-S.; Jain, S. Precipitation trends over the Korean peninsula: Typhoon-induced changes and a typology for characterizing climate-related risk. Environ. Res. Lett. 2011, 6, 034033. [CrossRef]

43. Villarini, G.; Smith, J.A.; Ntelekos, A.A.; Schwarz, U. Annual maximum and peaks-over-threshold analyses of daily rainfall accumulations for Austria. J. Geophys. Res. Atmos. 2011, 116. [CrossRef]

44. Villarini, G.; Smith, J.A.; Vecchi, G.A. Changing frequency of heavy rainfall over the central United States. J. Clim. 2013, 26, 351-357. [CrossRef] 
45. Rouse, J.W.; Haas, R.H.; Schell, J.A.; Deering, D.W. Monitoring vegetation systems in the Great Plains with ERTS. NASA Spec. Publ. 1974, 351, 309.

46. Tucker, C.J. Red and photographic infrared linear combinations for monitoring vegetation. Remote Sens. Environ. 1978, 8, 127-150. [CrossRef]

47. Huete, A.R.; Jackson, R.D. Soil and atmosphere influences on the spectra of partial canopies. Remote Sens. Environ. 1988, 25, 89-105. [CrossRef]

48. Zhao, A.; Zhang, A.; Liu, X.; Cao, S. Spatiotemporal changes of normalized difference vegetation index (NDVI) and response to climate extremes and ecological restoration in the Loess Plateau, China. Theor. Appl. Climatol. 2018, 132, 555-567. [CrossRef]

49. Huete, A.R.; Liu, H.; van Leeuwen, W.J. The use of vegetation indices in forested regions: Issues of linearity and saturation. In IGARSS'97. 1997 IEEE International Geoscience and Remote Sensing Symposium Proceedings. Remote Sensing-A Scientific Vision for Sustainable Development; IEEE: New York, NY, USA, 1997; pp. 1966-1968.

50. Mutanga, O.; Skidmore, A.K. Narrow band vegetation indices overcome the saturation problem in biomass estimation. Int. J. Remote Sens. 2004, 25, 3999-4014. [CrossRef]

51. Liu, G.; Liu, H.; Yin, Y. Global patterns of NDVI-indicated vegetation extremes and their sensitivity to climate extremes. Environ. Res. Lett. 2013, 8, 025009. [CrossRef]

52. Lotsch, A.; Friedl, M.A.; Anderson, B.T.; Tucker, C.J. Response of terrestrial ecosystems to recent Northern Hemispheric drought. Geophys. Res. Lett. 2005, 32. [CrossRef]

53. Zhou, Y.; Pei, F.; Xia, Y.; Wu, C.; Zhong, R.; Wang, K.; Wang, H.; Cao, Y. Assessing the Impacts of Extreme Climate Events on Vegetation Activity in the North South Transect of Eastern China (NSTEC). Water 2019, 11, 2291. [CrossRef]

54. Zheng, F.; Westra, S.; Leonard, M. Opposing local precipitation extremes. Nat. Clim. Chang. 2015, 5, 389-390. [CrossRef]

55. Guo, J.; Guo, S.; Li, Y.; Chen, H.; Li, T. Spatial and temporal variation of extreme precipitation indices in the Yangtze River basin, China. Stochas. Environ. Res. Risk Assess. 2013, 27, 459-475. [CrossRef]

56. Kabthimer, G.T. Assessment of Spatio-Temporal Patterns of Ndvi in Response to Precipitation Using Noaa-Avhrr Rainfall Estimate and Ndvi Data from 1996-2008, Ethiopia; Stockholm University: Stockholm, Sweden, 2012.

57. Almazroui, M. Rainfall trends and extremes in Saudi Arabia in recent decades. Atmosphere 2020, 11, 964. [CrossRef]

58. Almazroui, M.; Saeed, S. Contribution of extreme daily precipitation to total rainfall over the Arabian Peninsula. Atmos. Res. 2020, 231, 104672.1-104672.8. [CrossRef]

59. Liu, R. Compositing the minimum NDVI for MODIS data. IEEE Trans. Geosci. Remote Sens. 2016, 55, 1396-1406. [CrossRef]

60. Sun, Q.; Miao, C.; Qiao, Y.; Duan, Q. The nonstationary impact of local temperature changes and ENSO on extreme precipitation at the global scale. Clim. Dyn. 2017, 49, 4281-4292. [CrossRef] 